\title{
A conceptual framework for energy technology sustainability assessment
}

\author{
Josephine K. Musango \\ Resource Based Sustainable Development, Council for Scientific and Industrial Research, PO Box 320, \\ Stellenbosch, 7599, South Africa \\ Centre for Renewable and Sustainable Energy Studies; School of Public Leadership, Stellenbosch \\ University, Sustainability Institute, PO Box 162, Lynedoch, Stellenbosch, 7603, South Africa.
}

\begin{abstract}
Alan C Brent
Centre for Renewable and Sustainable Energy Studies; School of Public Leadership, Stellenbosch University, Sustainability Institute, PO Box 162, Lynedoch, Stellenbosch, 7603, South Africa.

This research is part of Josephine K. Musango, PhD, study on "Technology assessment of Renewable Energy Sustainability in South Africa", with Stellenbosch University, South Africa (www.tsama.org). The research forms part of a larger project of the Council for Scientific and Industrial Research (www.csir.co.za) that has established a Bioenergy Systems Sustainability Assessment and Management (BIOSSAM) portal (www.biossam.org).
\end{abstract}

Corresponding author. Resource Based Sustainable Development, Council for Scientific and Industrial Research, PO Box 320, Stellenbosch, 7599, South Africa. Fax: + 27218882696.

\begin{abstract}
Technology assessment has changed in nature over the last four decades from an analytical tool for technology evaluation, which depends heavily on quantitative and qualitative modelling methodologies, into a strategic planning tool for policy making concerning acceptable new technologies, which depends on participative policy problem analysis. The goal of technology assessment today is to generate policy options for solutions of organizational and societal problems, which, at the operational level, utilize new technologies that are publicly acceptable, that is, viable policy options. This study focuses on the development of a framework that incorporates a technology assessment approach, namely, system dynamics, within the broader scope of technology development for sustainability.

The framework, termed system approach to technology sustainability assessment (SATSA), integrates three key elements: technology development, sustainable development, and dynamic systems approach. The article then demonstrates the framework of incorporating the system dynamics methodology in energy technology assessment theory and practice within the context of sustainable development. The framework provides for technology sustainability assessment, which, in turn, can guide the promotion of sustainable energy technologies at a policy level. In
\end{abstract}


addition, it can assist technology developers in understanding the potential impacts of a technology, hence enabling them to reduce technology transfer risks.

\section{Keywords}

- Technology sustainability assessment;

- System dynamics;

- Sustainable development;

- Sustainable technology;

- Energy technologies

\section{Introduction}

Technological development has long been a key driver in the energy sector (Sagar and Holdren, 2002). Technology development is regarded as an interaction of the technology with the system in which the technology is embedded (Hekkert et al., 2007). Technology development not only has the potential of providing the advantage of economic growth and societal benefits but can also facilitate in minimizing the negative effects on the natural environment. The relation between the environment and technology is, however, complex and paradoxical (Grübler, 1998 and Grübler et al., 2002). Firstly, technologies use resources and impose environmental stress. On the other hand, technologies can also lead to more efficient use of resources and less stress on the environment. The latter approach is referred to as sustainable technology development (Weaver et al., 2000). Since sustainable technology development is not autonomous, its management is necessary.

One of the important disciplines in technology management is technology assessment (TA), which has evolved over the past four decades (Tran and Daim, 2008). TA enables the evaluation of the aggregate technology capability and facilitates strategic technology planning. Although TA does not necessarily provide policy makers and managers "the answer", it may improve the odds that the maximum benefits of technology will be achieved ( De Piante Henriksen, 1997). TA can reduce the risks inherent in the competitive process by providing information in support of decision making and can be important in determining research and development direction, new technologies adoption, incremental improvement in existing technologies, level of technology friendliness, 'make or buy' decisions, optimal expenditure of capital equipment funds, and market diversification ( De Piante Henriksen, 1997).

While TA has found value in many technology-related problems, there is still a strong need of finding more effective methods of assessment (Tran and Daim, 2008), especially in Africa. This is because TA does not feature in many African government policies (Musango and Brent, 2010). In South Africa, however, a Technology Innovation Agency (TIA), which is a stateowned body, was recently established (IT News, 2009). The agency has three critically important objectives (Engineering News, 2007 and Technology Innovation Agency Act of 2008, 2008). Firstly, it is to stimulate technology development; secondly, to stimulate the development of technological enterprises; and, finally, to stimulate the broader industrial base. However, without a formal comprehensive or well-integrated TA tool to evaluate sustainability of any technology, 
the policy makers, technology designers, and decision makers are faced with difficulty in terms of the appropriate technology options for the country.

Providing support for the development of sustainable energy innovations therefore remains a difficult task for decision makers with a need to influence the course of technological change.

This article therefore develops a conceptual framework of a systems approach to technology sustainability assessment (SATSA) with an aim of providing an improved assessment practices model for renewable energy technologies in developing countries. The framework can also ensure that technology development projects incorporate a broader range of considerations for achieving the desired sustainability performance. Through the framework, the basis of using system dynamics modelling as a means for technology sustainability assessment is explored, and the guiding steps for model development are provided using renewable energy technologies as a case.

\section{Proposed conceptual framework}

Fig. 1 provides a schematic representation of the proposed conceptual framework for technology sustainability assessment. The aim of the framework is to demonstrate the linkages between the key elements that are proposed as important for improved technology sustainability assessment practices. These are technology development, sustainable development, and dynamic systems approach. Pairing these elements renders the understanding of sustainable technology development, technology assessment, and sustainability assessment. On the other hand, integrating the three elements provides the foundation for SATSA.

\section{Technology development}

Technology has affected society and its environment in a number of ways. In many societies, technology has facilitated the development of more advanced economies, such as the current global economy, and the rise of a leisure class. However, many technological processes produce unwanted by-products, such as pollution, and deplete natural resources, both to the detriment of the natural environment. Also, various implementations of technology influence the values of a society and new technology often raises new ethical questions (see Text box 1 for an illustration).

The last 300 years have experienced more momentous technological changes than any other period and is considered as the "age of technology" ( Grübler, 1998). Anthropologists, historians, and philosophers were the first to have an interest in understanding the role technology plays in shaping societies and cultures. Individuals from other disciplines such as economics only followed later to study technological change ( Rosegger, 1996). Thorstein Veblen and Joseph A. Schumpeter pioneered the thinking on technology. Veblen, 1904, Veblen, 1921 and Veblen, 1953 was the first to focus on the interactions between humans and their artifacts in an institutional context and to regard technology as part of material and social relationships. Technology was deemed to be developed and shaped by social actors while at the same time shaping social values and behavior.

Schumpeter (1911), in turn, considered the sources of technological change as endogenous to the economy. This is well illustrated using Schumpeter's waves (see Fig. 2), whereby the duration in 
which the utilization of new technology knowledge influences the characteristics of economic development decreases. Technological change thus arises within the economic system as a result of newly perceived opportunities, incentives, deliberate research and development efforts, experimentation, marketing efforts, and entrepreneurship ( Grübler, 1998).

Currently, numerous technology studies acknowledge the feedback loops affecting technology development and a common conclusion that technology development is neither simple nor linear is shared. Grübler (1998) identifies four important characteristics of technology development that are relevant in guiding the development of the improved technology sustainability assessment; these are uncertainty, dynamic, systemic, and cumulative.

Technological uncertainty arises due to the existence of a number of solutions to achieve a particular task. It is thus uncertain which of these solutions might be the "best" when all economic, social, technical, and environmental factors are taken into account. Uncertainty also exists at all stages of technology development, from the initial design choices to success or failure in the market place. Secondly, technology is dynamic implying that it exhibits an s-curve as it changes over time as a result of improvements or modifications. Plotting the performance of a technology against the cost of investment initially shows a slow improvement, which is then followed by an accelerated improvement and finally diminishing improvement, as shown in Fig. 3. The factors contributing to the dynamic nature of technologies is due to either (i) the new inventions or (ii) continuous replacement of capital stock as it ages and economies expand. Technology development is systemic and cannot be treated as a discrete, isolated event. The interdependence of technologies causes enormous difficulties in implementing large-scale changes. The mutually interdependent and cross-enhancing "socio-technical systems of production and use” ( Kline, 1985) cannot be analyzed in terms of single technologies. This should be considered in terms of the mutual interactions among the concurrent technological, institutional, and social change. Finally, technology change is cumulative and builds on previous experience and knowledge.

Although the technology development characteristics discussed above are recognized in the literature, two fundamental features are still largely ignored by macroeconomic (Grübler, 1998) and other models. These are (i) evolution from within and (ii) the inherent dynamic and nonequilibrium nature of technological change, which the static and equilibrium models fail to capture.

\section{Sustainable development}

The concept of sustainable development has enjoyed widespread coverage in the literature and in discussions at diverse levels (Assefa and Frostell, 2007). The Brundtland Report, Our Common future ( World Commission on Environment and Development, 1987) and Goldemberg et al. (1988), Energy for sustainable world, are taken as a starting point in this study.

The most widely used definition of sustainable development refers to the three dimensions of sustainability: ecological, economic, and social systems. The concept of sustainability derives from a shift in perspective, from a focus on economic development that is often defined as the expansion of consumption and GDP to a new view of development called sustainable development (Harris and Goodwin, 2001). 
The Brundtland Report defines sustainable development as the development that meets the needs of the present generation without compromising the ability of future generations to meet their own needs (World Commission on Environment and Development, 1987). According to Mebratu (1998), this definition contains two key concepts: (i) the concept of "needs" particularly the essential needs of the world's poor, which requires a paramount priority, and (ii) the idea of limitations imposed by the state of technology and social organization on the ability of the environment to meet the present and future needs.

Other studies have argued that sustainable development is neither a fixed condition nor a final sustainable state but is inherently a dynamic process (Mog, 2004). Kemmler and Spreng (2007) illustrated this point by arguing that future generations, with greater knowledge and sophisticated technology and different needs, will define sustainable development in their own way and with a different set of development goals. In addition, Meadows (1998) recognizes sustainable development as depended on a society's worldviews and values.

Despite the debates and arguments around the concept of sustainable development, the conceptual priority is mainly sustaining the society and not explicitly the environment and the economy (Gaziulusoy et al., 2008). However, the irreversible hierarchical interdependencies depicted in Fig. 4 prescribe the environment as being the operational priority. This is because both the society and economy are dependent on the environment as the provider of the necessary resources. The time frame for use when planning for sustainable development is also debated in the literature. However, in accordance with the operational priority, the sustainable development concept intrinsically requires a long-term future orientation.

\section{Dynamic systems approach}

The dynamic systems approach is a technique for the computational modelling of complex, nonlinear systems. The aim of using a dynamic systems approach is to understand the ways in which systems function and the consequences that may follow as a result of the interconnectedness of system states (Auerhahn, 2008). Changes taking place in one part of the system may manifest impacts in others. System dynamics is the dynamic systems approach proposed in this study. It is an interdisciplinary approach that is based on the theory of system structures (Sterman, 2000). System dynamics represents complex systems and analyzes their dynamic behavior over time (Forrester, 1961). According to Coyle (1996): "system dynamics deals with the time dependent behaviour of managed systems with the aim of describing the system, and understanding, through qualitative and quantitative models, how information feedback governs its behaviour, and designing robust information feedback structures and control policy through simulation and optimization”. Thus, the main objectives of a system dynamics approach are (i) to clarify the endogenous structure of a particular system of interest under study, (ii) to identify the interrelationships of different elements of the system under study, and (iii) to account for different alternatives for simulation and explore the changes in the system under consideration.

The initial step in system dynamics modelling is to determine the system structure consisting of positive and negative relationships between variables, feedback loops, system archetypes, and delays (Sterman, 2000 and Wolstenholme, 2004). This is followed by an ex ante projection, where future system states are replicated from this model. Ex ante projection implies that uncertainties with regard to future changes in a system structure can be more easily addressed as 
there is better understanding of a system structure in the first place ( Sterman, 1994). This understanding of a system structure requires a focus on the system as a whole, and it is argued that a holistic system understanding is a necessary condition for the effective learning and management of complex systems, as well as consensus building. Additionally, systems modelling and simulation support policy analysis and evaluation ( Morecroft, 1988).

System dynamics models consist of qualitative/conceptual and quantitative/numerical modelling methods (Dolado, 1992). Qualitative modelling involves the use of causal loop diagrams or hexagons (Hodgson, 1992), which guides in improving the understanding of the conceptual system. Quantitative modelling implies the use of stock-and-flow models, and the investigation and visualization of the effects of different intervention strategies through simulation and optimization. Quantitative modelling also requires making explicit statements about assumptions underlying the model, identifying uncertainties with regard to system structure, and describing gaps in data availability. This whole process promotes model transparency.

\section{Combined elements}

Technology assessment

Eriksson and Frostell (2001) define technology assessment as "the evaluation of an object, function, or sequence of functions -created by human society to assist in achieving a goal - with respect to sustainability in comparison of other solutions providing the same function(s)”. Assessments of technology development are very important, especially for large-scale technologies, since a large amount of capital resource is required for their development. Rational and consistent assessments call for model analyses because of the complex characteristics of technology development as described in Section 2.1.

System dynamics is among the methods identified in the technology assessment literature (De Piante Henriksen, 1997 and Tran, 2007). The main benefit of using system dynamics for technology assessment is the increased realism in the assessment itself. The analysis of the other categories of technology assessment may not capture the complex real-world behavior of uncertainties that result from non-linear feedback structures, such as learning curves (Sterman, 2000). Modelling the structure of any technology with system dynamics that produces complex behavior of technology development may improve the accuracy of technology assessment.

Another advantage of using system dynamics in technology assessment is its flexibility in defining complex feedback systems and separate stochastic effects. This is essential and beneficial, especially when dealing with multiple and potentially interacting sources of uncertainty. In addition, describing the distribution of uncertainty around system dynamics variables is intuitive (Sterman, 2000). As a result, system dynamics provides clearer insights into the drivers of the effects of strategic action (Johnson et al., 2006) in technology development.

The number of studies that use a system dynamics model in technology assessment within the framework of sustainable development is limited. Chambers (1991), for example, used system dynamics to investigate the Australian chemicals, fuels, and energy industries. He used Forrester's system dynamics simulation model, coupled with the linear programming routine, for system optimization (Forrester, 1961). In recent years, however, the literature of technology 
assessment has increasingly recognized the benefits of using system dynamics. Wolstenholme (2003), for example, describes a holistic and dynamic method based upon system dynamics modelling for the early evaluation of technology at an intermediate and balanced level. This article provides a further example of a conceptual model of how technology assessment can be incorporated into system dynamics models for an intermediate level assessment.

\section{Sustainability assessment}

The main purpose of sustainability assessment is to provide decision makers with an evaluation of global to local integrated environment-economy and society systems from both short- and long-term perspectives (Kates et al., 2001). The aim of such an assessment is to provide guidance on policy actions that are intended to achieve sustainable development goals.

Since its inception, the concept of sustainable development has prompted policymakers to formulate new strategies for achieving balanced economic and technological pathways that would safeguard the environment, not only here and now but also elsewhere in the future (Nijkamp and Vreeker, 2000). New technologies may affect all the dimensions of sustainable development dimensions through their influence on the natural environment and on social and economic development (Huber, 2004). In addition, sustainability is context-specific and may ultimately be determined by the needs and opportunities in a given region as part of a broader spatial system.

Singh et al. (2009) provide an overview of the different methodologies for sustainability assessment. They identified the following approaches as an integrated assessment for sustainability: conceptual, system dynamics, multi-criteria, risk analysis, uncertainty, vulnerability, cost benefit, and impact assessment. Of all the methods that are categorized as integrated approaches, only system dynamics can account for the dynamic and inherent complexity of sustainable development sub-systems as discussed in Section 2.2. This feature of system dynamics in sustainability assessment is also discussed by Hjorth and Bagheri (2006), whereby they illustrate the appropriateness of the system dynamics approach to the problems of sustainable development.

\section{Sustainable technology development}

Technology determines to a large extent the demand for raw materials and energy, needs for further transport and infrastructure, mass flows of materials, emissions, and other forms of waste. Technology is, however, also a key factor of systems of innovation and influences prosperity, consumption patterns, lifestyles, social relations, and cultural developments. Technology can also improve the natural environment where damage has occurred. Therefore, the development, production, use, and disposal of technical systems have impacts on and benefits for the ecological, economic, and social (and other) dimensions of sustainable development.

Technology is always embedded in the sub-systems of the economy, society (and its institutions), and the natural environment, as they relate to sustainable development (see Fig. 5). The typical elements of a technology system include natural resources, organizational artifacts, physical artifacts, and legislative artifacts (Hughes, 1987), which entail sustainable development sub-systems. Thus, there is no deterministic relationship between technology system and the sustainable development subsystem. 
Borrowing from the co-evolution literature (Norgaard, 1984 and Norgaard, 1995), this can be regarded as the co-evolution of technology in sustainable development sub-systems. In terms of the co-evolution concept, the implication is that neither can technologies determine the future aspects of the sustainability of the sub-systems nor can technology sustainability be fully determined by the elements of sustainable development according to its intentions. Instead, the process is a complex one where technologies and the sustainable development sub-systems mutually influence each other, involving many different factors. When such interrelationships are taken into account, it is soon realized that ecological, economic, social, and technological sub-systems are (overall) complex systems. Although the interrelationships of these sub-systems can be analyzed in smaller scales by defining boundaries, any attempt to suggest sustainable technology development will be meaningless if such an analysis does not take the interdependencies into account.

Systems approach to technology sustainability assessment (SATSA)

Managing technology development for sustainability is a "wicked" problem, in the sense that there is no definitive formulation of sustainable development and more so no conclusively "best" technology solutions. In addition, the problems related to sustainable development are constantly changing. Despite these connotations, to be able to shape technologies towards sustainable development, it is important to begin with the sustainable development goals.

The definition of Eriksson and Frostell (2001) of the concept of technology assessment (refer to Section 2.4.1) suggests that technology should be assessed from a perspective of a certain defined setting, within which it is supposed to operate. This implies that technology assessment is important in relation to the operational level of sustainability because in its practical sense, sustainability entails measurement and performance comparison (Assefa and Frostell, 2006).

The study of Faber et al. (2005), to determine the conceptual foundations of sustainability, concludes that both theoretical (definitions) and practical (operationalization) contributions of the concept of sustainability evolved from being static/absolute to dynamic/relative. The static conceptualization assumes no change over time with the subject artefact itself and between other artefacts in its environment. An assessment is then carried out with the (general) assumption that the scientific knowledge is complete, and taking the present socio-cultural values, technological limitations, and resource limits into consideration. However, the dynamic conceptualization of sustainability realistically assumes that both internal and external changes will occur. From this perspective, in order to undertake a technology assessment that considers all the aspects of sustainability, it is important to acknowledge the complexity and the co-evolution of technology within sustainability sub-systems. The system dynamics approach thus provides a suitable platform for analysing technology development within the sustainable development framework.

From a technology sustainability assessment perspective (Assefa and Frostell, 2006), system dynamics recognizes sustainability as a whole systems concept concerned with human activities in the context of naturally occurring systems that provide the sources and sinks for the flows of materials and energy associated with them. It also shows the ability of those systems to sustain human activities in the future, including further technology development (Chan et al., 2004). 
The relevance of the systems approach to technology sustainability assessment (SATSA) for energy technologies

While energy technology assessment is not new, it has become more relevant in recent times than before (Daim et al., 2009). Energy technology development is an iterative and reflexive process requiring accumulated knowledge combined with the utilization of both natural and human capital. Sustainable energy technology development requires the consideration of the following aspects:

a) Sustainable energy technology development intrinsically demands long-term planning. This is because the required change is hard to achieve within a short-time frame due to the large extent of complexity of the interaction of energy systems with the sustainable development sub-systems. The Millennium Institute illustrates such an interaction as presented in Fig. 6.

b) Sustainable development sub-systems and technology development demonstrate complexity that cannot be reduced to linearity, which certainly applies to energy technology development.

c) A co-evolutionary approach is required to understand the effects of interactions taking place both within and between the energy technology development system and sustainable development sub-systems in order to be able to influence change towards a desired path.

d) Both the technology development and sustainable development concepts are dynamic. Therefore, the requirements and characteristics for sustainable energy technology development change over time. This is due to new information and knowledge that are gathered and changes taking place within energy technology development and sustainable development sub-systems.

e) Radical change at energy technological level is required. This is mainly influenced by sustainable development sub-systems.

In order to undertake an energy technology assessment that accounts for sustainable development sub-systems, the approach, method, or tool used should therefore be capable of (i) providing a long-term coverage; (ii) addressing complexity; (iii) dealing with co-evolutionary changes both as a result and cause; (iv) allowing continuous feedback, reassessment, and adjustment to cope with the dynamic characteristics and changing requirements of sustainability concept; and (v) providing a creative vision to guide the technology development path towards the radical change.

The system dynamics is a dynamic systems approach capable of accounting for the above mentioned issues. Thus, system dynamics provides a vital element for energy technology development as well as planning for sustainable development. 
Methodology description of the systems approach to technology sustainability assessment (SATSA) for energy technologies

Having discussed the relevance of SATSA for energy technologies, this section provides the guiding process and steps of SATSA for energy technologies as presented in Fig. 7. The process allows the assessment of energy technology development accounting for sustainable development sub-systems and the relevant sustainability indicators and goals.

Step 1: sustainable technology development

STEP 1, which is denoted as "sustainable technology development", consists of two main activities. The first one is the identification of the need for energy technology development. As an example, if electricity generation technologies are considered, this activity will entail collecting information about the available electricity generation technology options in a particular country or region. The second activity of Step 1 is defining the sustainability goals of the energy technology development. Taking the example of electricity generation, this activity involves the identification of the linkages of electricity generation technologies with the sustainable development sub-systems, collection of information about the resource availability for electricity generation technologies, and the related economic, environmental, and social conditions. This information is necessary in order to populate the environmental, economic, and social impact indicators related to a specific technology development. It is important to note that some indicators may be directly related to a specific technology under consideration. On the other hand, other indicators are dependent on the economic, environmental, social, and political context in which the technology is being implemented.

Step 2: system dynamics modelling

Step 2, denoted as "system dynamics modelling”, consists of three main activities, namely modelling the domain of energy technology application, new energy technology assessment, and technology accommodation in the energy sector domain. These activities mentioned are comparable to the three-stage methodology to technology assessment of Wolstenholme (2003). However, unlike Wolstenholme (2003), this article proposes a Step 1, sustainable technology development, whereby there are interlinkages with the system dynamics modelling. This is because the identification of the energy technology options and their respective desired sustainability performance/goals should be defined before the system dynamics modelling.

\section{Model the domain of energy technology application}

The first activity of Step 2 involves developing a base system dynamics model. Again, taking the example of electricity generating technologies, in this step, one would aim at populating, calibrating, and validating a system dynamics model of the current structure of the electricity generation technologies. This would include both the conventional and renewable energy technologies. In addition, unlike Wolstenholme (2003), the proposed system dynamics modelling activity also includes the structure of the interlinkages between the energy technology system with the sustainable development sub-systems. An essential aim of this activity is to improve the understanding of sustainable energy technology development in a particular country or region under consideration. 
The second activity is the assessment of new energy technology. The technology might not be new per se in the sense that it has never existed before. This may include technologies that have never been introduced in the particular country or region but are considered as potential options as identified in Step 1. The energy technology assessment activity is also based on the sustainable development goals identified in Step 1. This second activity of system dynamics modelling enables one to holistically learn the extent to which the new energy technologies promote the achievement of the desired sustainable development goals in a country or region.

\section{Technology accommodation in the energy sector domain}

The third activity is the critical one in the sense that it attempts to experiment on the ways in which the new technology can be accommodated in the current situation to achieve the desired sustainable development goals. It involves testing what changes in policies and procedures or modifications in the technology that may help in achieving these desired goals.

\section{Conclusions}

This article developed a conceptual framework for technology sustainability assessment, which the authors have termed as the systems approach to technology sustainability assessment (SATSA). Achieving sustainable technology development requires developing approaches or methods that account for the characteristics of the technology development and sustainable development sub-systems. System dynamics is the proposed dynamic systems approach that can guide in providing technology sustainability assessment.

SATSA lies at the cross-section of technology development, sustainable development, and dynamic systems approach. This implies that a dynamic systems approach can provide the necessary guidance in understanding the system boundaries for long-term technology development within the context of sustainable development criteria or goals. A guiding process or procedure for SATSA, using energy technology assessment as an example, was presented. SATSA is currently being applied to evaluate alternative energy options in the African context, which form part of the strategy of the New Partnership for Africa's Development (NEPAD) to reach the Millennium Development Goals.

\section{Acknowledgment}

The authors would like to acknowledge Dr. Bamikole Amigun for his valuable comments on an earlier version of the article. Council for Scientific and Industrial Research is acknowledged for providing funding to undertake this study. 
Figures and Tables

\section{Text Box 1}

An illustration of the effect of technology on society and environment.

From fossil fuel to renewable energy technologies.

Fossil fuels such as coal, natural gas, and crude oil have contributed to the sophistication of the society for many decades. However, these energy technologies have posed the unintended effects. Burning of oil and coal for all these decades led to greenhouse gas emission to the atmosphere that exceeds the earth's absorptive capacity. The world is at crossroads in determining the future energy technology development. Renewable energy, such as wind, solar, wave, tidal, and geothermal provide an alternative pathway for sustainable energy development. Thus, the choice between fossil fuel and renewable energy technologies poses ethical questions. 
Figures

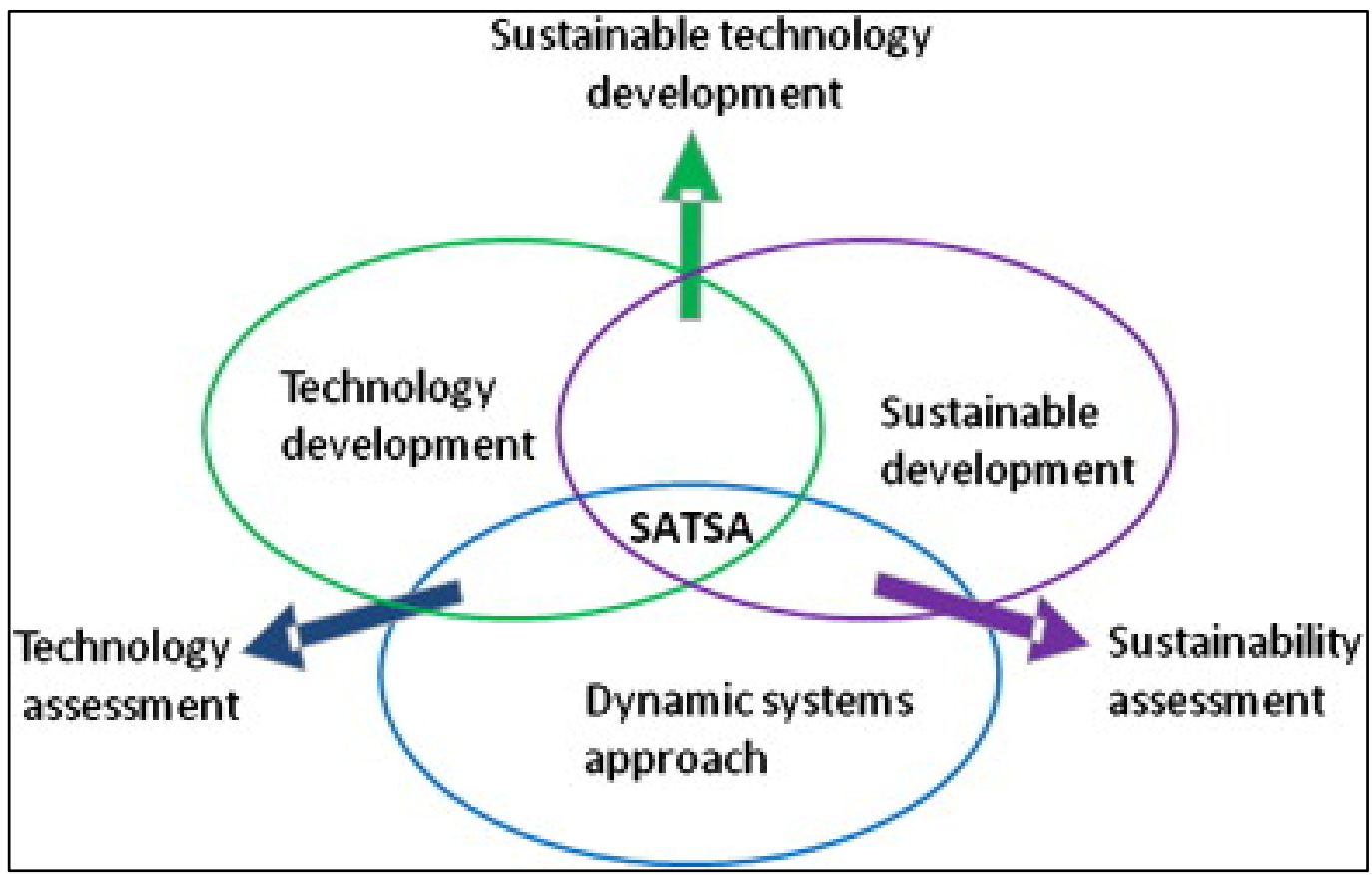

Fig. 1 Schematic representation of a systems approach to technology sustainability assessment ( SATSA ).

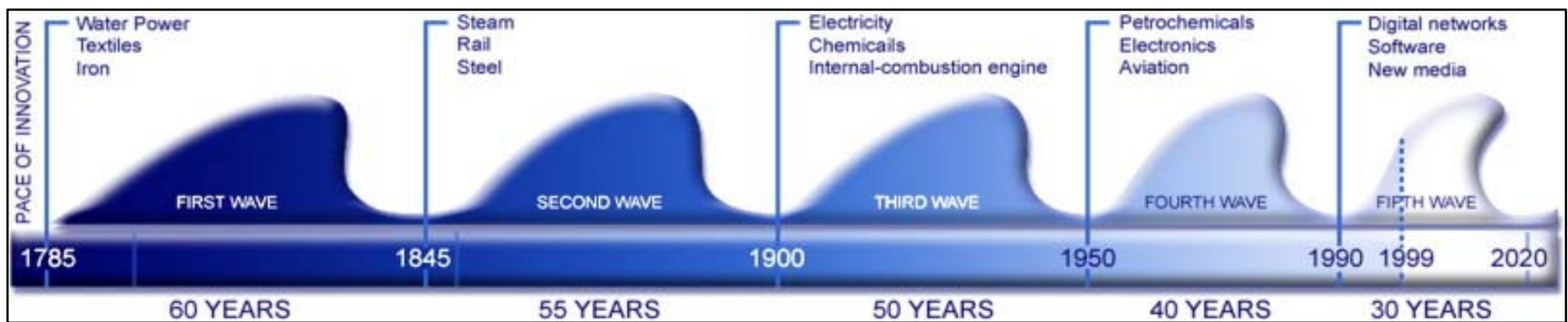

Fig. 2 Schumpeter waves of impact of the technological change on the economy. 


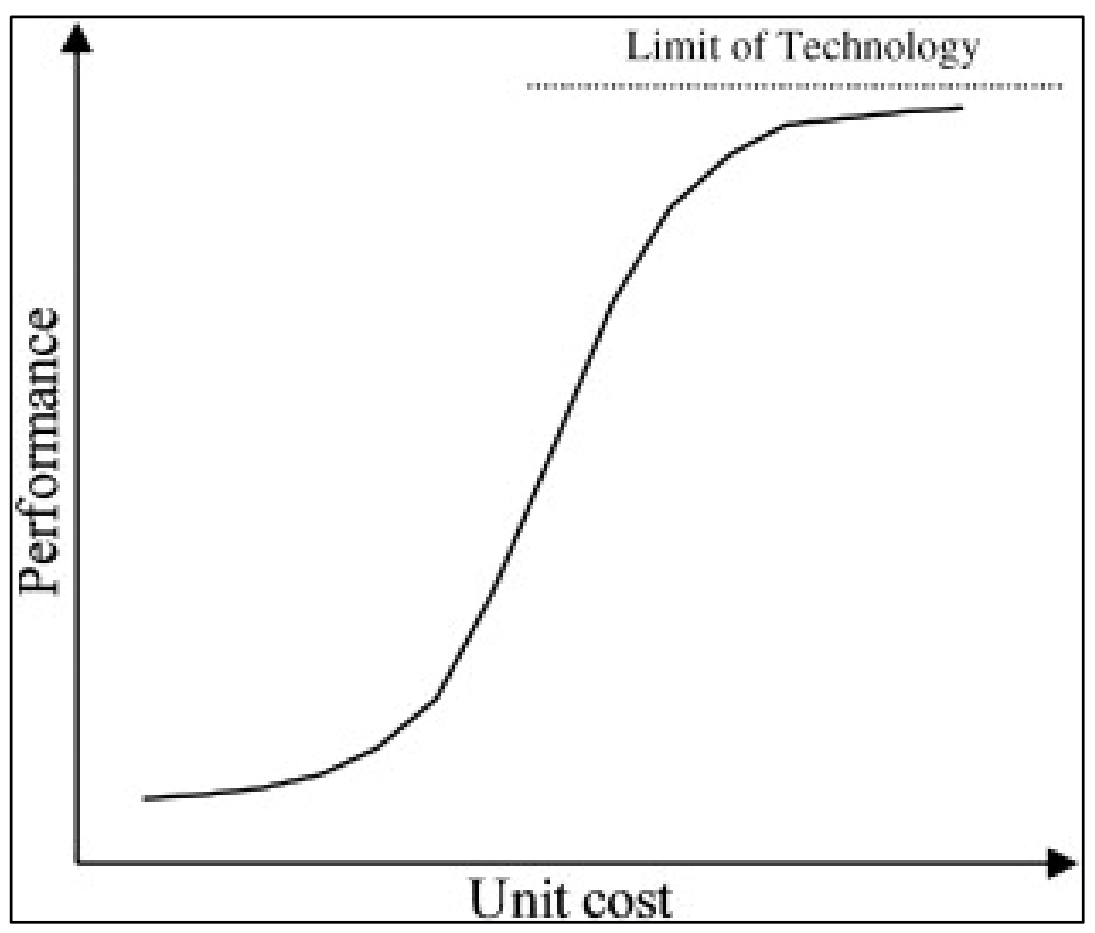

Fig. 3 Technology S-curve. 


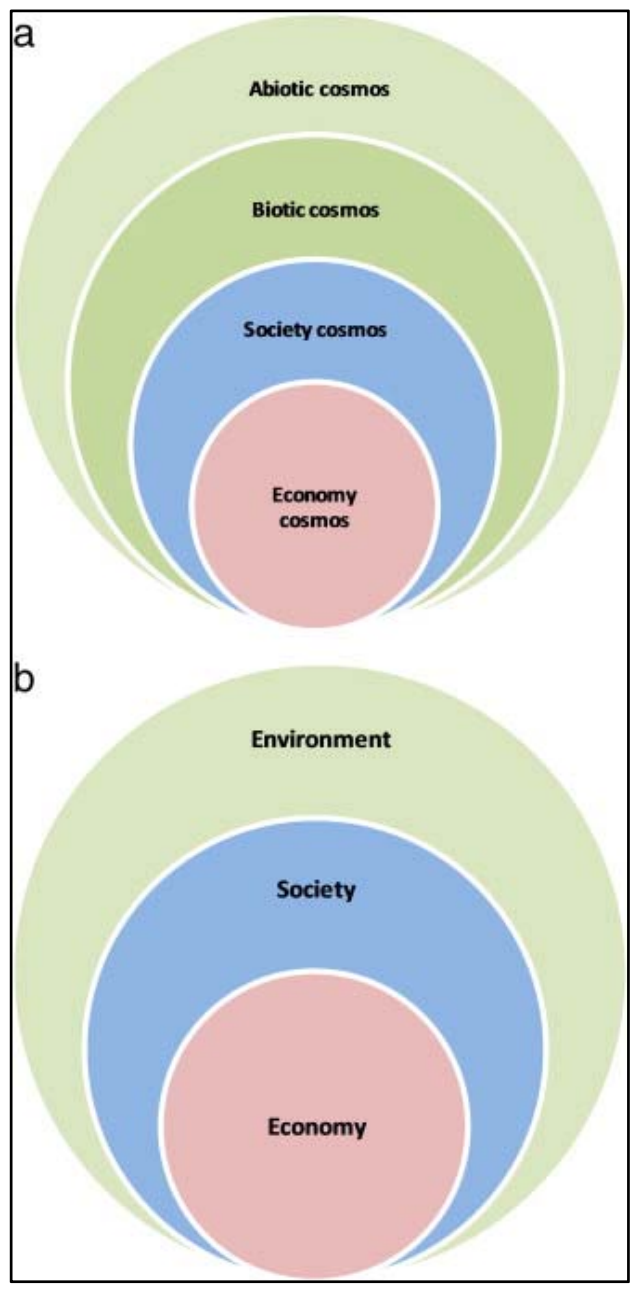

Fig. 4 (a) The cosmic interdependence; (b) operational priority of sustainabl e development model. <ce:source> Source: adapted from Mebratu D: Sustainability and sustainable development: Historical and conceptual review. Environmental Impact ... 


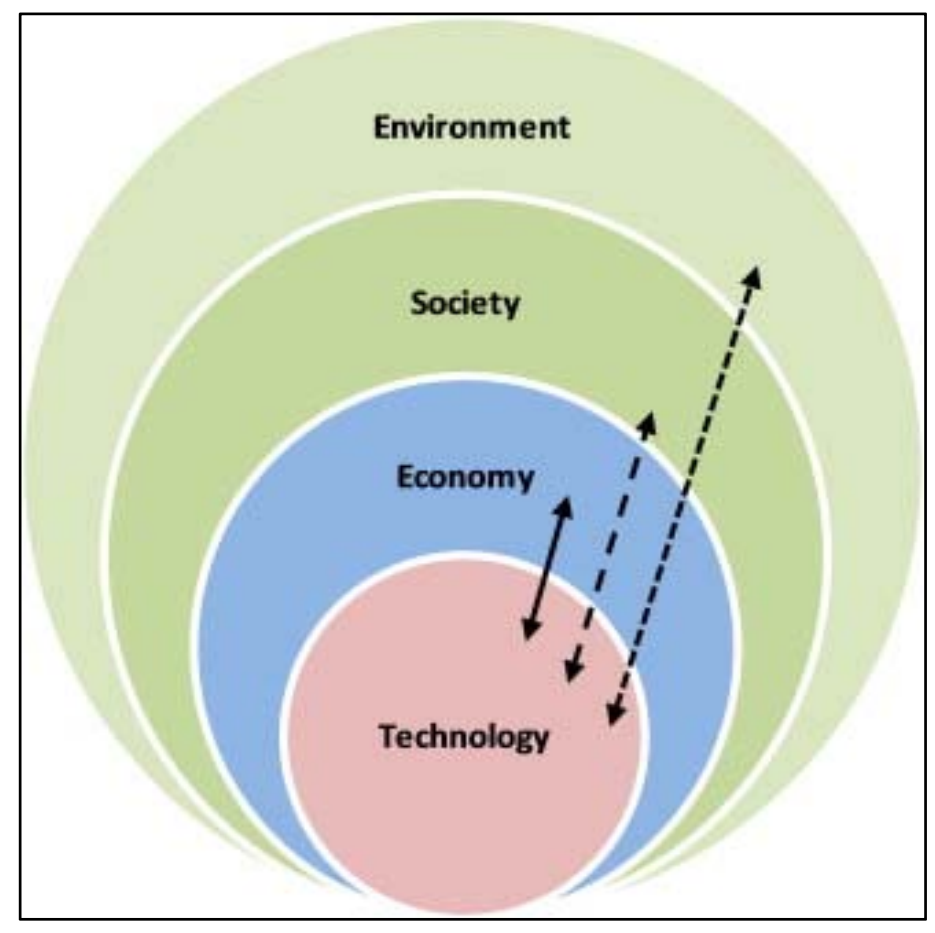

Fig. 5 Co-evolution of technology and sustainable development sub-systems.

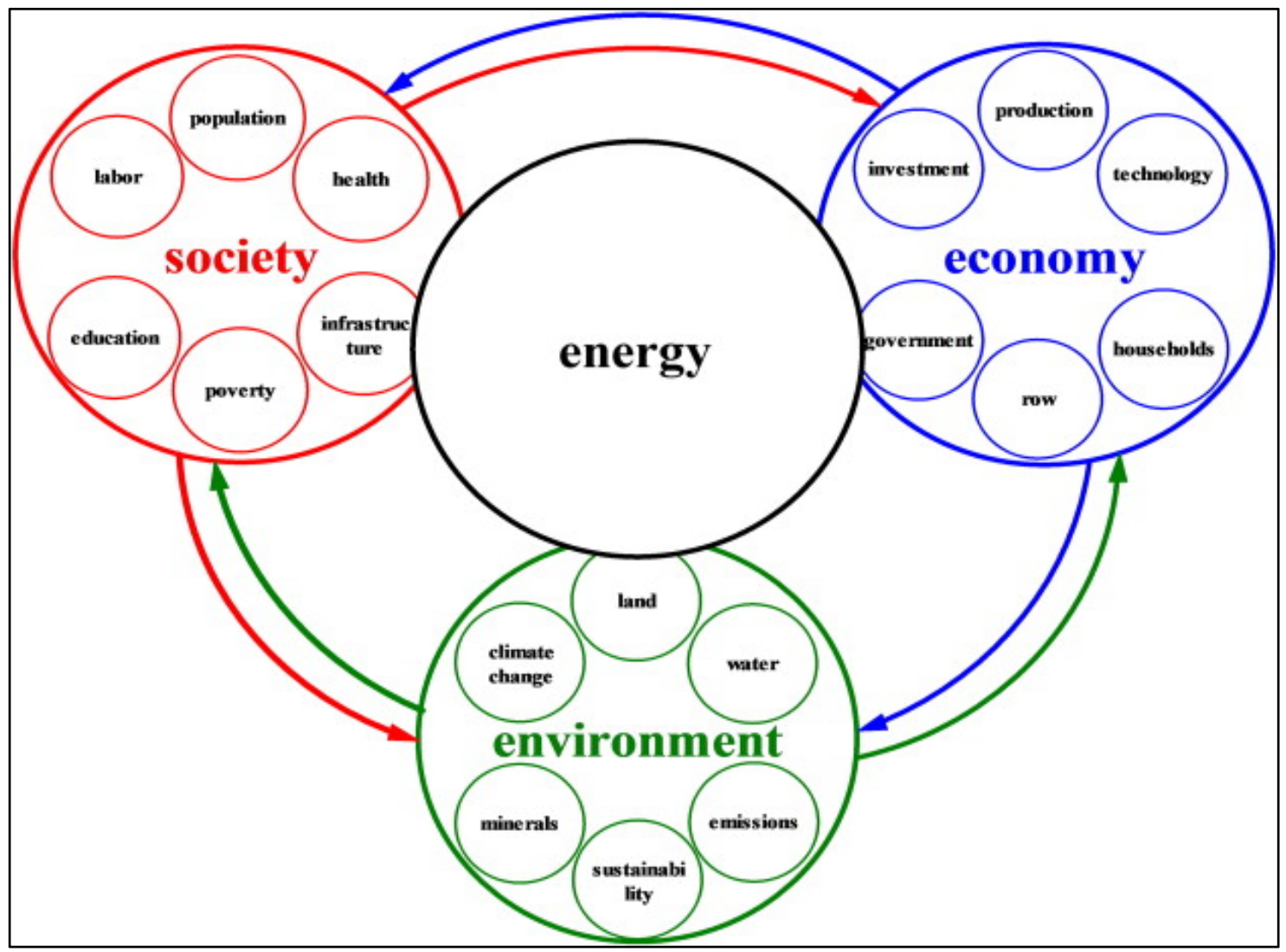

Fig. 6 Interrelationships between energy systems and sustainable development sub-systems. <ce:source> Source: Millennium Institute (<ce:inter-ref href="http://http://www.millenniuminstitute.net" type="simple"> http://www.millenniuminstitute.net</ce:inter-... 


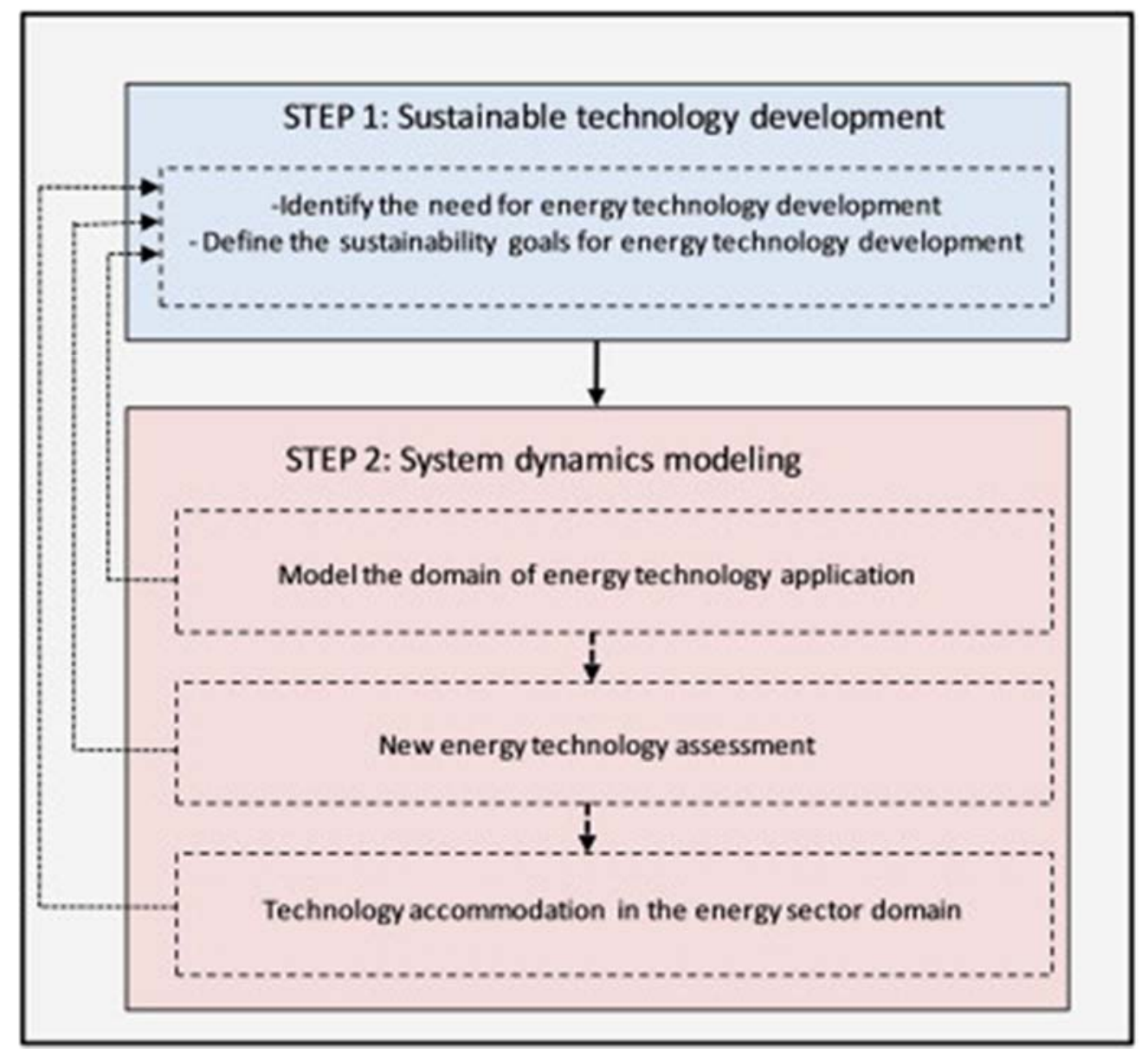

Fig. 7 Guiding process for SATSA : energy technology case. 


\section{References}

Assefa and Frostell, 2006 G. Assefa, B. Frostell Technology assessment in the journey to sustainable development G. Mudacumura, D. Mebratu, M.S. Haque (Eds.), Sustainable development policy and administration USA, Taylor and Francis Group (2006), pp. 473-502

Assefa and Frostell, 2007 G. Assefa, B. Frostell Social sustainability and social acceptance in technology assessment: a case study of energy technologies Technol. Soc., 29 (2007), pp. 63-78

Auerhahn, 2008 K. Auerhahn Dynamic systems simulation analysis: a planning tool for the new century J. Crim. Justice, 36 (2008), pp. 293-300

Bassi, 2009 Bassi, A., 2009. An integrated approach to support energy policy formulation and evaluation. PhD Thesis, University of Bergen.

Chambers, 1991 M.R. Chambers Planning for technological substitution and change Int. J. Prod. Econ., 25 (1991), pp. 191-200

Chan et al., 2004 Chan, A.W., Hoffman, R., Mcinnis, B., 2004. The role of systems modeling for sustainable development and policy analysis: the case of bio-ethanol. Ecology and Society, 9, 6 [online] URL: http://www.ecologyandsociety.org/vol9/iss2/art6.

Coyle, 1996 R.G. Coyle System dynamics modelling Chapman and Hall, London (1996)

Daim et al., 2009 T. Daim, D. Yates, Y. Peng, B. Jimenez Technology assessment for clean energy technologies: the case of the Pacific Northwest Technol. Soc., 31 (2009), pp. 232-243

De Piante Henriksen, 1997 A. De Piante Henriksen A technology assessment primer for management of technology Int. J. Technol. Manage., 13 (1997), pp. 615-638

Dolado, 1992 J.J. Dolado Qualitative simulation and system dynamics Syst. Dyn. Rev., 8 (1992), pp. 55-81

Engineering News, 2007 Engineering News, 2007. New agency to stimulate technology to grow the economy < http://www.engineeringnews.co.za/article/new-agency-to-stimulate-technology-to-growthe-economy-2007-07-27>; [accessed 8.07.09].

Eriksson and Frostell, 2001 O. Eriksson, B. Frostell An approach to sustainability assessment of energy systems S. Silveria (Ed.), Building sustainable energy systems: Swedish experiences, Stockholm, Sweden, Swedish National Energy Administration (2001)

Faber et al., $2005 \mathrm{~N}$. Faber, R. Jorna, J. Van Engenlen The sustainability of 'sustainability'-a study into the conceptual foundations of the notion of sustainability J. Environ. Assess. Policy Manage., 7 (2005), pp. 1-33

Forrester, 1961 J.W. Forrester Industrial dynamics Productivity Press, Cambridge, MA (1961) 
Gaziulusoy et al., 2008 A.I. Gaziulusoy, C.A. Boyle, R. McDowall A conceptual systemic framework proposal for sustainable development: incorporating future studies within a co-evolutionary approach Civ. Eng. Environ. Syst., 25 (2008), pp. 301-311

Goldemberg et al., 1988 J. Goldemberg, T.B. Johansson, A.K.N. Reddy, R.H. Williams Energy for a sustainable worldWiley Eastern, New Delhi (1988)

Grübler, 1998 A. Grübler Technology and global change Cambridge University Press, Cambridge (1998)

Grübler et al., 2002 A. Grübler, N. Nakicenovic, W.D. Nordhaus Technological change and the environment Resources for the Future, Washington, DC (2002)

Harris and Goodwin, 2001 J.M. Harris, N.R. Goodwin Volume introduction, in: M.H. Jonathan, A.W. Timothy, P.G. Kevin, R.G. Neva (Eds.), A survey of sustainable development: social and economic dimensions, frontier issues in economic thought, Vol. 6lsland Press, Washington (2001) pp. xxvii

Hekkert et al., 2007 M. Hekkert, R. Suurs, S. Negro, S. Kuhlmann, R. Smits Functions of innovation systems: a new approach for analysing technological change Technological Forecasting Soc. Change, 74 (2007), pp. 413-432

Hjorth and Bagheri, 2006 P. Hjorth, A. Bagheri Navigating towards sustainable development: a system dynamics approach Futures, 38 (2006), pp. 74-92

Hodgson, 1992 A.M. Hodgson Hexagons for systems thinking Eur. J. Oper. Res., 59 (1992), pp. 220-230

Huber, 2004 J. Huber New technologies and environmental innovation Edward Elgar, Cheltenham (2004)

Hughes, 1987 T.P. Hughes The evolution of large technological systems W.E. Bijker, T.P. Hughes, T. Pinch (Eds.), The social construction of technological systems, Cambridge, MIT Press (1987), pp. 51-82

IT News, 2009 IT News, 2009. New Technology Innovation Agency for South Africa. http://www.itnewsafrica.com/?p=2425; [accessed 8.07.09].

Johnson et al., 2006 Johnson, S.T., Taylor, T., Ford, D., 2006. Using system dynamics to extend real options use: insights from oil and gas industry, < https://ceprofs.civil.tamu.edu/dford/DNF\%20Profesional/SDandROatBPforSDconfRevised060426.pdf> ; [accessed 08.02.2010].

Kates et al., 2001 R.W. Kates, W.C. Clark, R. Corell, J.M. Hall, C.C. Jaeger, I. Lowe, J.J. McCarthy, H.J. Schellnhuber, B. Bolin, N.M. Dickson, S. Faucheux, G.C. Gallopin, A. Grubler, B. Huntley, J. Jager, N.S. Jodha, R.E. Kasperson, A. Mabogunje, P. Matson, H. Mooney, B. Moore, T. O'riordan, U. Svedin Environment and development: sustainability science Science, 292 (2001), pp. 641-642

Kemmler and Spreng, 2007 A. Kemmler, D. Spreng Energy indicators for tracking sustainability in developing countries Energy Policy, 35 (2007), pp. 2466-2480

Kline, 1985 S.J. Kline What is technology? Bull. Sci. Technol. Soc., 5 (1985), pp. 215-219 
Meadows, 1998 Meadows, D., 1998. Indicators and information system for sustainable development. A report to the Balaton Group.

Mebratu, 1998 D. Mebratu Sustainability and sustainable development: historical and conceptual review Environ. Impact Assess. Rev., 18 (1998), pp. 493-520

Mog, 2004 J.M. Mog Struggling with sustainability-a comparative framework for evaluating sustainable development programmes World Dev., 26 (2004), pp. 2139-2160

Morecroft, 1988 J.D.W. Morecroft System dynamics and microworlds for policy makers Eur. J. Oper. Res., 35 (1988), pp. 301-320

Musango and Brent, 2010 J.K. Musango, A.C. Brent Assessing the sustainability of energy technological systems in Southern Africa: a review and way forward, Paper presented at the 19th International Conference for Management of Technology, Cairo, Egypt, 8-11 March 2010 (2010)

Nijkamp and Vreeker, 2000 P. Nijkamp, R. Vreeker Sustainability assessment of development scenarios: methodology and application to Thailand Ecol. Econ., 33 (2000), pp. 7-27

Norgaard, 1984 R.B. Norgaard Coevolutionary development potential Land Econ., 60 (1984), pp. 160-173

Norgaard, 1995 R.B. Norgaard Development betrayed: the end of progress and a coevolutionary revisioning of the future Routledge, London/NewYork (1995)

Rosegger, 1996 P.M. Rosegger The economics of production and innovation: an industrial perspective Butterworth Heinemann Ltd, Oxford, UK (1996)

Sagar and Holdren, 2002 A.D. Sagar, J.P. Holdren Assessing the global energy innovation system: some key issues Energy Policy, 30 (2002), pp. 465-469

Schumpeter, 1911 J.A. Schumpeter Theorie der wirtschaftlichen Entwicklung (translated in 1934, The theory of economic development: an inquiry into profits, capital, credit, interest and business cycles) Harvard University Press, Cambridge (1911)

Singh et al., 2009 R.K. Singh, H.R. Murty, S.K. Gupta, A.K. Dikshit An overview of sustainability assessment methodologies Ecol. Indic., 9 (2009), pp. 189-212

Sterman, 1994 J.D. Sterman Learning in and about complex systems Syst. Dyn. Rev., 10 (1994), pp. 291330

Sterman, 2000 J.D. Sterman Business dynamics: systems thinking and modelling for a complex world McGraw-Hill/Irwin, New York (2000)

Technology Innovation Agency Act of 2008, 2008 Technology Innovation Agency Act of 2008, 2008.

< http://www.info.gov.za/view/DownloadFileAction?id=92827>; [accessed 30.04.2010].

Tran, 2007 Tran, T. A., 2007. Review of methods and tools applied in technology assessment literature. 
Tran and Daim, 2008 T.A. Tran, T. Daim A taxonomic review of methods and tools applied in technology assessment Technological Forecasting Soc. Change, 75 (2008), pp. 1396-1405

Veblen, 1904 T. Veblen The theory of business enterprise Scribner, New York (1904)

Veblen, 1921 T. Veblen The engineers and the price system Huebsch, New York (1921)

Veblen, 1953 T. Veblen The theory of leisure class: an economic study of institutions New American Library, New York (1953)

Weaver et al., 2000 P. Weaver, L. Jansen, G. Grootveld, E. Spiegel, P. Van Sustainable technology development Greenleaf Publishing, Sheffield, UK (2000)

Wolstenholme, 2004 E.F. Wolstenholme Using generic system archetypes to support thinking and modelling Syst. Dyn. Rev., 20 (2004), pp. 341-356

Wolstenholme, 2003 E.F. Wolstenholme The use of system dynamics as a tool for intermediate level technology evaluation: three case studies J. Eng. Tech. Manage., 20 (2003), pp. 193-204

World Commission on Environment and Development, 1987 World Commission on Environment and Development Our common future Oxford University Press, Oxford (1987) Also known as the Brundtland Report 